\title{
Methacrylic Resin for Protection of Wood from Discoloration by Mould Growth and Weathering
}

\author{
Injeong Kim,* Olov Karlsson, Olena Myronycheva, Dennis Jones, and Dick Sandberg
}

The discoloration of uncoated wood surfaces in both outdoor and indoor use in non-heated spaces has become an increasing problem in European timber constructions due to the use of less toxic substances for protection and also changes in outdoor climate conditions, necessitating the use of protective coatings. To investigate the effect of methyl methacrylic (MMA) resin for the protection of wood from discoloration and mould growth, resin-treated wood surfaces were studied in a laboratory-scale mould test, as well as in an outdoor weathering test. Non-modified Scots pine and Norway spruce were used, and some of the test materials were also thermally modified. The resin suppressed mould growth for the laboratoryscale experiments. The protective effect was considerably reduced for outdoor tests. The MA resin did not effectively prevent the wood from greying from ultraviolet (UV) radiation exposure; there was some protective effect detected on the pine. The Fourier transform infrared (FTIR) spectra of weathered specimens showed a reduction of ligninassociated absorption bands for all treatments, which corresponded to the UV degradation and greying of the wood surface. It is suggested that MMA resin may provide adequate protection against mould growth on wood without direct exposure to rain and sunshine (e.g., attics, basements, etc).

Keywords: Methacrylic resin; Scots pine; Norway spruce; Thermally modified timber; FTIR; Mould

Contact information: Wood Science and Engineering, Luleå University of Technology, Forskargatan 1, 931 87 Skellefteå, Sweden; *Corresponding author: Injeong.kim@ltu.se

\section{INTRODUCTION}

Wood can be a very durable material against different types of degradation, but its durability depends upon the circumstances, such as the environment, where the wood is in use, the type of wood, and how it has been protected. In constructions where wood-based building materials are not exposed to extreme chemical or thermal environments, wood durability is mainly related to biological, physical, and photochemical degradation mechanisms on its exposed surfaces or its interior, which can reduce its function and/or appearance. High durability is also important as it is often related to lowered maintenance costs.

The biological degradation of wood in northern Europe is mainly due to wooddestroying fungi (e.g., white-rot, brown-rot and soft-rot fungi), which can not only degrade the structure of wood and have a significant effect on functional properties, but also influence the appearance of the wood material by discoloration. Degradation may also occur with discoloring or mould fungi, which as their name suggest, result in deterioration in appearance without impacting mechanical performance. However, the presence of discoloring and mould fungi may be a prelude to subsequent attack by wood-destroying fungi (Brischke and Unger 2017). Mould fungi can also induce allergic reactions in humans and, as a consequence, it is important to prevent mould growth in buildings. Mould growth 
is usually related to the accessibility of nutrients and moisture to these microorganisms, as well as ventilation and condensation (Brischke and Unger 2017). Mould can grow indoors, especially in areas that have limited heating and airflow, such as inside the attic and basement, as well as outside where the wood may be exposed to higher levels of humidity or rain.

The conventional method to prevent fungal growth is to apply a toxic preservative, such as a copper-based agent. However, due to their toxicity to humans and to the environment, many of these preservatives are banned or need to be substituted. Alternative wood modifications and biocides based on an organic system have been proposed to substitute conventional preservatives. To prevent mould, compounds, such as 3-iodo-2propynyl butylcarbamate (IPBC), diiodomethyl-p-tolylsulfone (e.g., Amical 48), and examples of isothiazolinones are used. However, these compounds are only capable of protecting the wood for a short period (Schultz et al. 2007); hence, a better solution for the protection of wood against mould is needed.

Besides mould growth, the discoloration of wood can occur due to different abiotic factors. During outdoor exposure, wood is degraded and discolored by a combination of ultraviolet (UV) radiation, water or moisture, and elevated temperatures. This results in internal stresses and degradation mainly at the surfaces of the wood, resulting in reductions of the material's service life (Forest Products Laboratory 1975). Because of the limited ability of radiation to penetrate into the wood, the effect of the UV degradation is limited to a region approx. $2.5 \mathrm{~mm}$ beneath the wood's surface; also, wood erosion is slow, i.e., 5 to $12 \mathrm{~mm}$ per 100 years (Browne and Simonson 1957; Feist and Mraz 1978).

When wood absorbs light, its color change depends on the components that interact with the light. All major components of wood are sensitive to UV radiation; cellulose strongly absorbs radiation between 200 to $300 \mathrm{~nm}$, while lignin and polyphenols (i.e., extractives) strongly absorb light below $200 \mathrm{~nm}$ and at $280 \mathrm{~nm}$. Lignin is responsible for 80 to $95 \%$ of the total light absorption coefficient for wood (Norrström 1969; Gierer and Lin 1972; Hon 1981; Hon and Minemura 2001), and its degradation is believed to proceed rapidly via the formation of radicals that oxidize phenolic units to chromophoric structures, such as unsaturated and conjugated carbonyl structures (Feist and Hon 1984; Pandey and Vuorinen 2008). These conjugated chromophoric structures are not stable to further exposure to UV-radiation. They will be degraded and finally removed from the middle lamella of the cell wall, resulting in wood surfaces with loosely attached fibres with low chroma. Therefore, the color starts to change more or less directly when the surface is exposed to UV radiation, with a grey hue developing as the lignin degradation products are washed away (Feist and Hon 1984).

This discoloration and/or degradation is typical for uncoated wood surfaces; however, the same behaviour occurs with thermally modified timber (TMT) surfaces. The thermal modification process of wood is most frequently used today to give a durable and dimensionally stable material with an initial brownish color (Jones et al. 2019). The brownish color is related to the degradation of the hemicelluloses and lignin during the modification process (Esteves and Pereira 2008), and the color can be varied by the choice of wood species and process conditions (International ThermoWood Association 2003; Bekhta and Niemz 2005). The chromophores present in TMT before and after UV radiation exposure are not known in detail, but a study (Tolvaj et al. 2014) showed that thermal modification processes reduced the red color discoloration during photodegradation, whilst limiting changes in yellow color associated with lignin degradation. It was concluded that thermal modification provided a slight improvement in photodegradative stabilization. 
TMT has been found to be more durable against biological degradation than unmodified timber, possibly due to the reduced levels of easily accessible nutrients. The presence of quickly metabolised sugars and methanol-soluble extractives has been shown to be lower in TMT processed under open superheated conditions versus TMT processed under closed and saturated steam conditions (Karlsson et al. 2012a, 2012b; Sidorova et al. 2018).

Because lignin and polyphenols are the wood constituents most susceptible to photodegradation, attempts to increase the UV-stability of lignin in wood have been accomplished with benzophenones (Kiguchi and Evans 1998; Olsson et al. 2012) and with UV-absorbers, such as hindered amine light stabilizers (HALS), in conjunction with Tinuvin ${ }^{\circledR}$ lignin radical stabilisers (Schaller and Rogez 2007; Forsthuber et al. 2013). Reactions using benzoyl chloride (Pandey and Chandrashekar 2006; Pandey and Srinivas 2013), vinyl benzoate (Jebrane et al. 2009), acetylation of wood, and treatment with certain chromium compounds (Evans 2009) can also reduce the discoloration of weathered wood. Iron-based salts with or without oxidants can influence the color of TMT during weathering (Karlsson and Morén 2010). The addition of pigments into an oil coating of TMT can improve its color stability (Jämsä et al. 2000). Silicon-based sol-gel (Mahltig et al. 2010) and $\mathrm{TiO}_{2}$ and $\mathrm{ZnO}$ nanoparticles can improve color stability, but the latter can also lead to increased cracking of the waterborne polyacrylate film coating during both outdoor and artificial exposure (Miklečić et al. 2015). Methyl methacrylate (MMA) is known to increase the hardness of wood; it has also been suggested that it has a stabilizing effect on wood degradation by UV radiation (Feist et al. 1991).

MMA is a monomer that is produced on a large scale for the production of poly(methyl methacrylate). It has been used to improve the dimensional stability of wood; however, the effect of MMA resin is limited because the monomer does not easily penetrate into the cell walls (Ellis and O'Dell 1999). Some studies on the application of MMA to wood have shown an improvement of the dimensional stability, surface characteristics, and density (Koubaa et al. 2012; Li et al. 2012).

MMA has a distinctive acrid odour that makes it difficult to handle. Karlsson et al. (2018) have suggested applying a commercial MMA-based resin to improve the resistance of wood to mould growth. Colonisation of such microorganisms on surfaces in wood constructions may not only influence their aesthetic appearance but may also cause health problem for residents.

The purpose of the present study is to investigate the possibility of applying commercial MMA-based resin to untreated and thermally-modified wood to improve its resistance to mould growth and to surface discoloration when exposed outdoors for a limited period of weather exposure (for example during the construction of a wooden building). Based on the results of the experiments, examples of the use of the treatment system in wooden constructions are proposed.

\section{EXPERIMENTAL}

Two different tests were performed: an outdoor weathering test with wood specimens of dimensions of $20 \mathrm{~mm} \times 100 \mathrm{~mm} \times 150 \mathrm{~mm}$ (length $(\mathrm{L}) \times$ width $(\mathrm{W}) \times$ height $(\mathrm{H})$ ), and an in vitro mould test with wood specimens of dimensions of $45 \mathrm{~mm} \times 22 \mathrm{~mm} \times$ $5 \mathrm{~mm}(\mathrm{~L} \times \mathrm{W} \times \mathrm{H})$. 


\section{Materials}

For the in vitro mould test, unmodified and thermally modified Scots pine sapwood timbers were used. The TMT used was modified in saturated steam at $170{ }^{\circ} \mathrm{C}$; it was obtained from Thermoplus (Arvidsjaur, Sweden). All specimens were cut to the dimensions of $45 \mathrm{~mm} \times 22 \mathrm{~mm} \times 5 \mathrm{~mm}(\mathrm{~L} \times \mathrm{W} \times \mathrm{H})$ and were oven-dried before testing.

For the outdoor weathering test, boards of Scots pine (Pinus sylvestris L.) and Norway spruce (Picea abies (L.) Karst.) with cross-section dimensions of $25 \mathrm{~mm} \times 105$ $\mathrm{mm}$ and moisture content of $15 \%$ were obtained from a local sawmill (Martinsons Trä AB, Bygdsiljum, Sweden). The boards were cut and planed to the dimensions of $150 \mathrm{~mm} \times 100$ $\mathrm{mm} \times 20 \mathrm{~mm}(\mathrm{~L} \times \mathrm{W} \times \mathrm{H})$ and were subsequently conditioned $\left(20^{\circ} \mathrm{C}\right.$ and $65 \%$ relative humidity $(\mathrm{RH})$ ) until the specimens reached a constant mass. In addition, the thermally modified timber of Scots pine and Norway spruce, modified by the ThermoWood ${ }^{\circledR}$ process in superheated steam at $212{ }^{\circ} \mathrm{C}$ (Dagbro et al. 2010), were obtained from Heatwood AB (Hudiksvall, Sweden); these specimens were prepared in the same way as the unmodified specimens.

A commercial methacrylate resin together with an accelerator (Cactus Juice Stabilizing Resin) was purchased from Turntex, LLC (San Marcos, TX, USA). Heatsensitive accelerator was mixed with the resin (1:50) prior to submersion coating of the wood specimens. Benzophenone (CAS No. 199-61-9) and malt-extract agar media (CAS No. 8002-48-0) were purchased from Merck KGaA (Darmstadt, Germany).

\section{Methods}

In vitro mould test

To observe the effect of the MMA resin treatment on wood, specimens were tested with respect to mould growth under laboratory conditions with pure fungal cultures.

An oven-dried specimen was submerged in the resin for $10 \mathrm{~min}$, which was followed by heating at $103{ }^{\circ} \mathrm{C}$ for $1 \mathrm{~h}$. The weight percentage gain (WPG) of the specimens due to the resin treatment is shown in Table 1. Prior to placement on petri dish, all specimens were sterilized by steam $\left(120^{\circ} \mathrm{C}, 152 \mathrm{kPa}\right)$ for $20 \mathrm{~min}$.

Spore suspensions ( $\mathrm{ca} .10^{6}$ spores/mL) with four different fungi were produced: Aureobasidium pullulans (De Bary) G. Arnaud, Cladosporium cladosporioides (Fresen.) G.A. de Vries, Aspergillus niger Van Tieghem, and Penicillium commune Thom; all were obtained from the culture collection at the division of Wood Science and Engineering, Luleå University of Technology, Luleå, Sweden.

The specimens treated with MMA resin were paired with the untreated specimens in the same Petri dish. The suspension produced was then sprayed onto the surfaces of each Petri dish in the amount of $0.3 \mathrm{~mL}$ using an airbrush with a pressure of 2 bar. The Petri dishes were then covered with a lid and stored in a climate chamber $\left(24{ }^{\circ} \mathrm{C}\right.$ and $\left.90 \% \mathrm{RH}\right)$. The visual evaluation of fungal growth was assessed after 7 days of exposure. All specimens in the Petri dishes were stored for two months.

\section{Outdoor weathering test}

The cross-sections of all the specimens were end-sealed with a commercial polyurethane-based sealant, Sikaflex ${ }^{\circledR}$, obtained from AT Connection (Sika Sverige, Sweden). Half of the specimens from the untreated and the thermally modified timber groups were submerged in the resin for $10 \mathrm{~min}$. Unmodified spruce specimens treated with a resin that contained $3 \%$ benzophenone were included. After immersion, the excess resin was wiped gently from the surfaces; then the specimens were heated to cure the resin 
standing on one of its cross-section surfaces in a ventilated oven at $70{ }^{\circ} \mathrm{C}$ for $1 \mathrm{~h}$, followed by $90{ }^{\circ} \mathrm{C}$ heating for $1 \mathrm{~h}$ (Karlsson et al. 2018). In this way, the exudation of resin from the board and the evaporation of volatile compounds in specimens could be suppressed during the curing treatment. The WPG due to the MMA resin after curing is shown in Table 1. Each treatment group contained five replicates. The different test groups are described in Table 2.

Table 1. Oven-dried Density of Specimens Before the Resin Treatment and WPG After the Curing of the MMA resin

\begin{tabular}{|c|c|c|c|}
\hline Test Group & No. of Specimens & $\begin{array}{c}\text { Oven-dried Density } \\
\left(\mathbf{k g} / \mathbf{m}^{3}\right)^{*} \\
\text { Mould Test }\end{array}$ & $\begin{array}{c}\text { WPG of MMA resin } \\
(\%)^{\star}\end{array}$ \\
\hline Scots pine sapwood & 5 & $468(15.10)$ & $10.5(1.40)$ \\
\hline Scots pine TMT & 5 & $415(31.11)$ & $5.0(0.52)$ \\
\hline Scots pine sapwood & 5 & Weathering Test \\
\hline Scots pine TMT & 5 & $507(22.1)$ & $11.4(1.16)$ \\
\hline Spruce & 5 & $443(49.1)$ & $4.6(1.40)$ \\
\hline Spruce TMT & 5 & $470(63.0)$ & $9.4(0.28)$ \\
\hline
\end{tabular}

* Standard deviation in parenthesis

Table 2. Test Groups for the Outdoor Weathering Test

\begin{tabular}{|c|c|c|c|}
\hline Test Group & Species & Modification & Treatment \\
\hline P & Pine sapwood & Unmodified & Untreated \\
\hline PM & Pine sapwood & Unmodified & Resin \\
\hline S & Spruce & Unmodified & Untreated \\
\hline SM & Spruce & Unmodified & Resin \\
\hline SMU & Spruce & Unmodified & Resin + benzophenone \\
\hline TP & Pine & ThermoWood & Untreated \\
\hline TM & Pine & ThermoWood & Resin \\
\hline TS & Spruce & ThermoWood & Untreated \\
\hline TSM & Spruce & ThermoWood & Resin \\
\hline TSU & Spruce & ThermoWood & Resin + benzophenone \\
\hline
\end{tabular}

The specimens were weighed and placed outdoors on racks facing south at a $45^{\circ}$ inclination at Luleå University of Technology $\left(64.744453^{\circ} \mathrm{N}, 20.955569^{\circ} \mathrm{E}\right)$. The outdoor test was performed between 11 July 2018 and 1 October 2018. On 4 September (55 days), the specimens were placed vertically in the northern direction in the rack. The growth of the mould was observed and visually assessed.

\section{Color measurement}

The exposed surface color of all the specimens from the outdoor weathering test was measured with a colorimeter (Chroma meter CR-410; Konica Minolta, Tokyo, Japan). The $L^{*}, a^{*}$, and $b^{*}$ color coordinates were measured from the centre of the board with a measuring head diameter of $5 \mathrm{~cm}$. The hue angle $\left(h\left(^{\circ}\right)\right)$ and chroma $\left(C^{*}\right)$ were computed from the coordinates. The $h$ value represents a visual sensation according to which a surface appears to be similar to a perceived color; it is computed as: 


$$
h=\arctan \left(b^{*} / a^{*}\right) .
$$

The $C^{*}$ value is defined as the strength of the hue and it is computed as:

$$
C^{*}=\sqrt{\left(a^{*}\right)^{2}+\left(b^{*}\right)^{2}} .
$$

The overall color difference $(\Delta E)$ was calculated as:

$$
\Delta E=\sqrt{\left(L^{*}\right)^{2}+\left(a^{*}\right)^{2}+\left(b^{*}\right)^{2}} .
$$

\section{Weather data during the test}

The weather data collected during the experiment is shown in Fig. 1., and is from a weather station at Balderskolan, Skellefteå $\left(64.7519^{\circ} \mathrm{N}, 20.9433^{\circ} \mathrm{E}\right)$ (Balderväder 2020). The intensity of sun light was determined each day as the sum of 48 measurements during $24 \mathrm{~h}$.

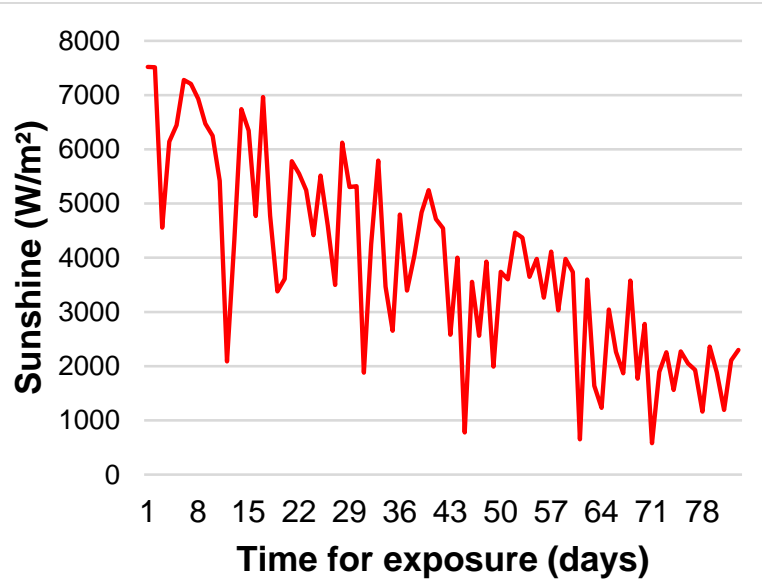

- Sunshine

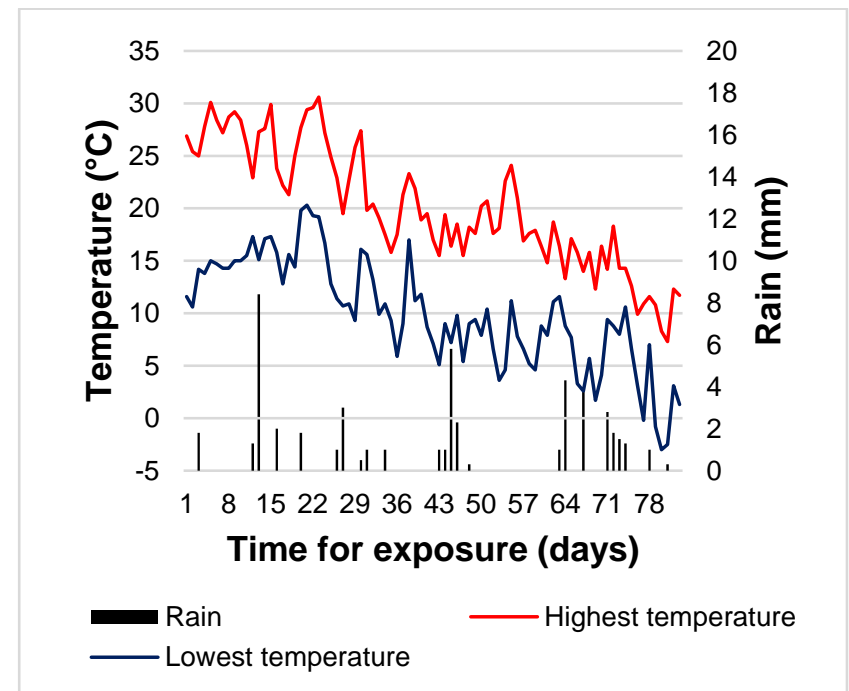

Fig. 1. The amount of sunshine and rain during the outdoor weathering test

Fourier transform infrared spectra (FTIR) spectra

To study the stability of the MMA resin and the changes in wood components as a result of weathering, the attenuated total reflection (ATR), which used a diamond crystal, was determined with a PerkinElmer Frontier ${ }^{\mathrm{TM}}$ FTIR spectrometer (Waltham, MA, USA). The IR spectra over the wavenumber range of 4000 to $450 \mathrm{~cm}^{-1}$ were collected using 4 scans with a resolution of $4 \mathrm{~cm}^{-1}$. All spectra were normalised with respect to the strongest absorption band (1023 to $1030 \mathrm{~cm}^{-1}$ ). Small scrapes were randomly taken from sites on the surface of the exposed and the unexposed specimens, and the scrapes were tested applying a similar pressure.

\section{Statistical analysis}

To determine the significance of difference between treatment groups and measurements of different dates within groups, all results were determined with analysis of variance (ANOVA). The significance of difference between mean values was determined at $5 \%$ difference $(p=0.95)$. 


\section{RESULTS AND DISCUSSION}

\section{In vitro Mould Test}

The investigation of fungal growth of pure cultures in a conditioning chamber revealed that the resin treatment appreciably delayed fungal colonisation of the surfaces (Table 3). In general, the growth of Aspergillus niger was greater than that of the other fungal species. This observation could have been due to the method of inoculation. According to previous studies (Myronycheva et al. 2018, 2019), the spraying technique chosen in the present study combined with the freely available water provided a favourable environment for Aspergillus niger, but less for other fungal species, such as Aureobasidium pullulans and Cladosporium cladosporioides, or "dry adhesion" fungus-like Penicillium commune, which commonly grow on timber outdoors (Fig. 2).

Table 3. Proportion of Specimens Where the Surfaces were Covered with Mould One Week After Inoculation

\begin{tabular}{|c|c|c|}
\hline & Scots Pine Sapwood $(\%)^{*}$ & ${\text { TMT }(\%)^{*}}^{*}$ \\
\hline Untreated & $100(0)$ & $78.2(23.82)$ \\
\hline MMA resin-treated & $19.7(28.53)$ & $6.5(9.97)$ \\
\hline
\end{tabular}

* Standard deviation in parentheses

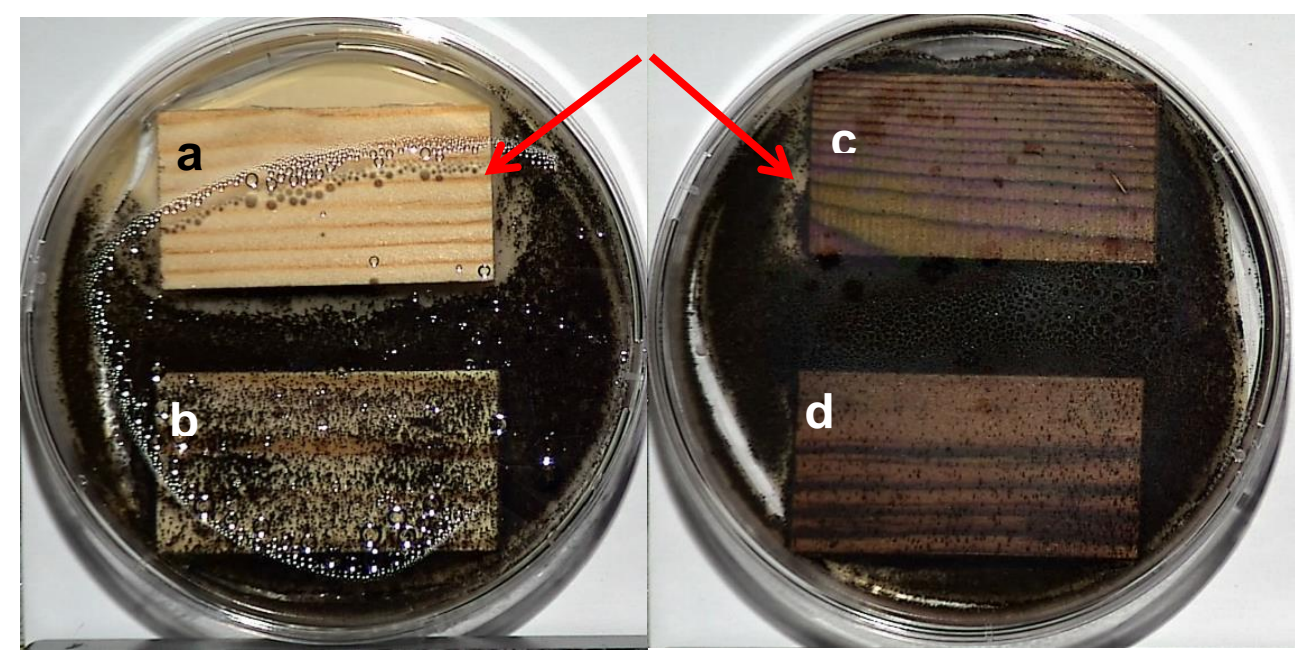

Fig. 2. Example of Petri dishes showing specimens sprayed with a mixture of moulds and evaluated after one week of conditioning: a) pine treated with MMA resin, b) untreated pine, c) thermally modified pine treated with MMA resin, and d) thermally modified pine (the red arrows indicate less mould in the surrounding nutrient medium)

\section{Mould Growth on Specimens During Outdoor Weathering}

The specimens after the weathering test are shown in Figs. 3 and 4. Mould growth was observed on unmodified pine and spruce after 41 days of exposure; however, specimens treated with MMA resin showed no visible mould until 75 days of exposure, which was two weeks after turning the specimens towards the north. The mould growth can be seen in Figs. 3 and 4 as a darker area on the exposed untreated pine, and to some extent, on the spruce, whereas the MMA-treated surfaces were less affected. 

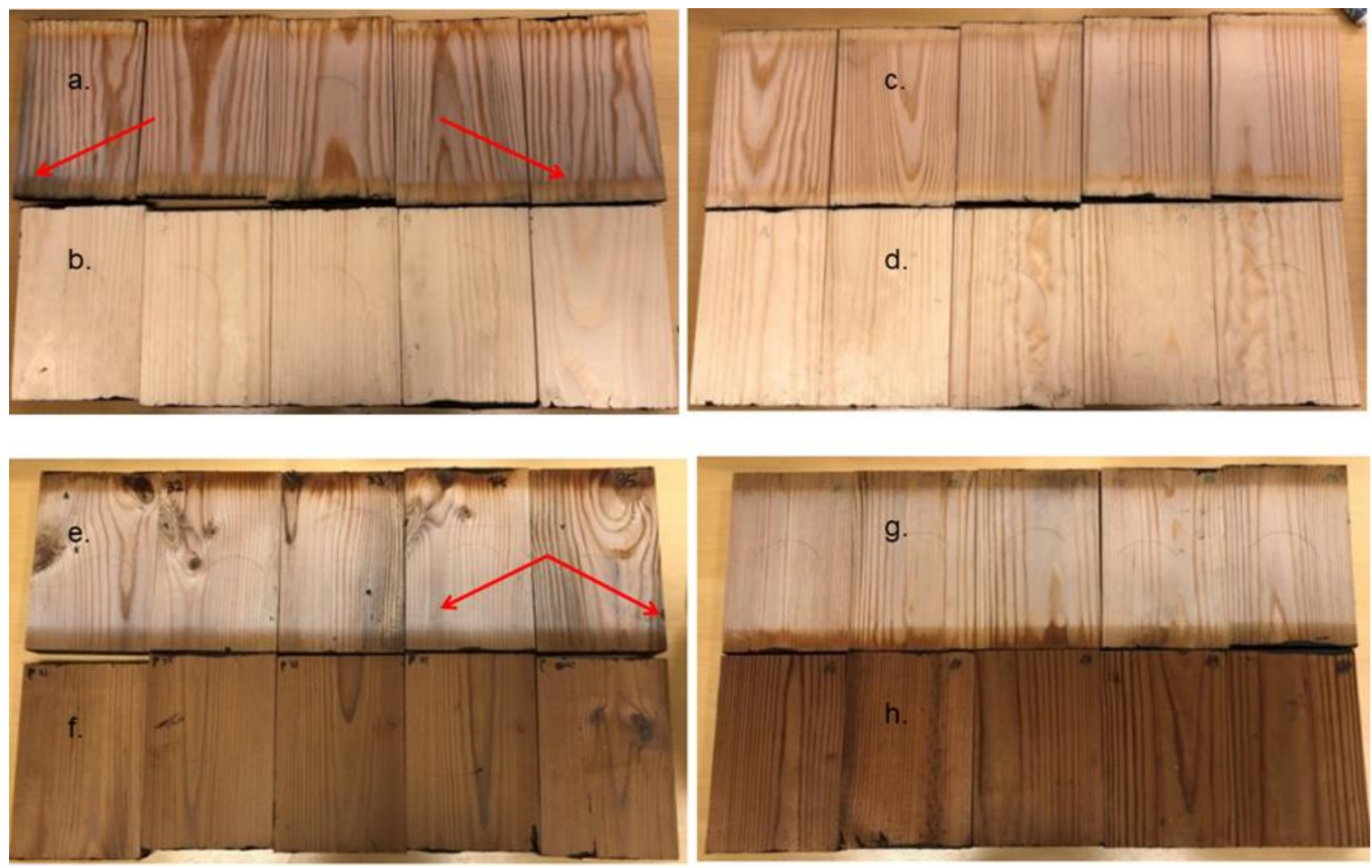

Fig. 3. Scots pine specimens before weathering (unexposed) and after 82 days of outdoor weathering. In each picture, weathered specimens are shown in the upper row (a, c, e, and g) and the same unexposed specimens are shown in the bottom row (b, $d, f$, and $h$ ) of untreated pine ( $a$ and $b$ ), pine treated with MMA resin ( $c$ and $d$ ), thermally modified pine (e and $f$ ), and thermally modified pine treated with MMA resin ( $g$ and $h$ )
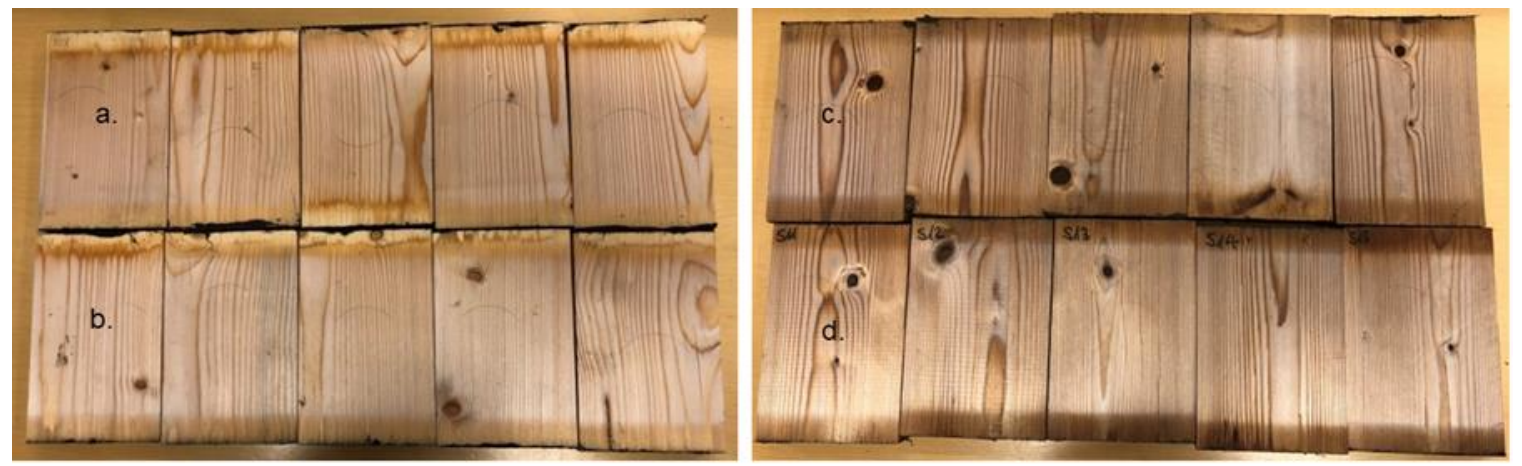

Fig. 4. MMA resin-treated spruce specimens (top (a and $c)$ ) and untreated spruce specimens (bottom ( $b$ and $d)$ ) of unmodified (left ( $a$ and $b$ ) and thermally modified (right ( $c$ and $d)$ ) after 82 days of outdoor weathering

\section{Color Changes Due to Outdoor Weathering Test}

All the specimens showed greying after outdoor weathering (Figs. 3 and 4). This observation was most evident for the TMT. The greatest change in color was observed after the first seven days of exposure, even though the weather conditions for first few weeks were fairly similar (Fig. 1). The rapid initial change followed by gradual change in color was also observed in previous studies (Nzokou and Kamdem 2006; Tomak et al. 2018). The MMA resin treatment provided no protection against greying (Figs. 3 and 4).

The color coordinate data agreed with the visual observation. The change in color coordinates of the unmodified wood surfaces as a result of outdoor weathering is shown in 
Fig. 5. The color change indicators $\left(\Delta E, \Delta L^{*}\right.$, and $\left.\Delta C^{*}\right)$ of specimens were more intensive during the first than the succeeding weeks of exposure. The lightness $\left(\Delta L^{*}\right)$ of exposed specimens decreased during the exposure until the second week when it started to stabilize. The darkening of the surface could be related to the formation of new oxidized lignin degradation products (Hon and Minemura 2001). The intensity or depth of color can be expressed as chroma $\left(C^{*}\right)$, which increased the first week of exposure but mostly decreased thereafter until the final weeks of exposure. Hue $(h)$ decreased with exposure period until about 20 days of exposure which indicates that the color of the specimens becomes less yellow but more red. From the $20^{\text {th }}$ day to the $41^{\text {st }}$ day of exposure, hue stabilized and then started to decrease again on further exposure. The reason for this behaviour was not easily understood but was attributed to a sudden change in the weather conditions and was not further evaluated. Addition of a few percent benzophenone did not improve the color stability of the MMA-treated specimens. In general, the resin-treated pine showed fewer changes in the color coordinates than the other specimens. The lightness and total discoloration are known to be affected by the number of water-soluble extractives that can act as antioxidants and can protect the wood from photodegradation (Nzokou and Kamdem 2006); additionally, the resin seemed to create a physical barrier that prevented watersoluble extractives from being washed out of the wood during outdoor exposure. However, the effect of the MMA resin was not as evident in the spruce samples as in the pine samples (Fig. 5).
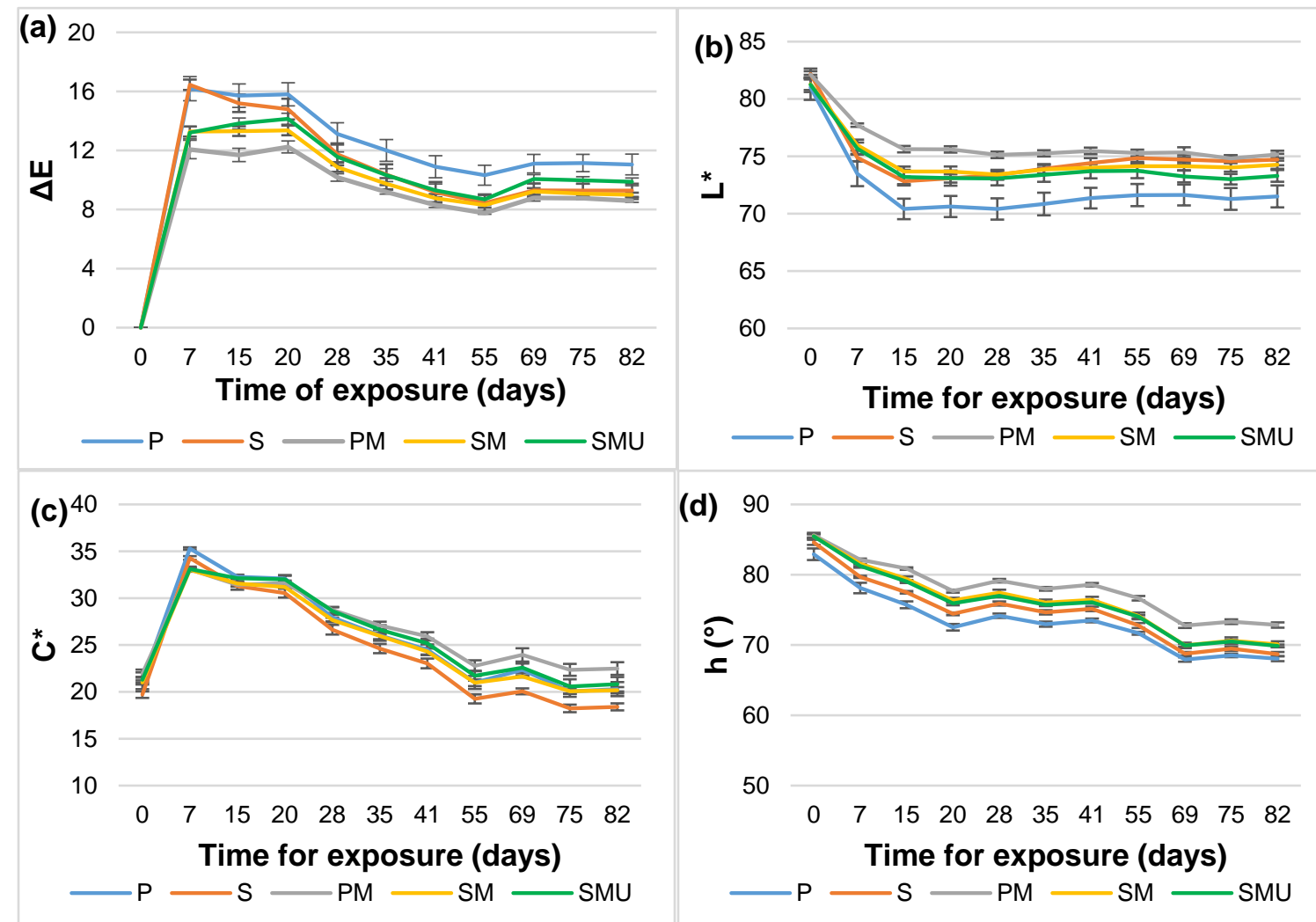

Fig. 5. Color differences over time for pine (P), spruce (S), pine treated with MMA resin (PM), spruce treated with MMA resin (SM), and spruce treated with MMA resin and benzophenone (SMU) during outdoor weathering; a) overall color difference $(\Delta E)$, b) lightness $\left(L^{*}\right)$, c) chroma $\left(C^{\star}\right)$, and d) hue angle $(h)$ 
The color coordinates of the thermally modified specimens changed in general more than those of the unmodified specimens during the outdoor exposure (Fig. 6). The thermally modified specimens showed initial rapid change of color similar to that of unmodified specimens, followed by a continuous change in both chroma and lightness during the test period. This tendency was also shown in previous studies (Srinivas and Pandey 2012; Shen et al. 2016). After 55 days, the values of the coordinates were even more stable, which may have been due to a decrease in sunlight exposure after the specimens were turned towards the north. The fairly rapid increase in hue in contrast to the more even decrease in hue for unmodified pine indicated a shift towards a more yellow color, which could mean that the chromophore systems in the thermally modified specimens were fairly quickly converted to other types, perhaps less extended ones, but still somewhat color intensive (Figs. 3 and 4). The intensity of the color decreased, however, with increasing exposure, which can be seen as a decrease in the chroma of the thermally modified specimens.
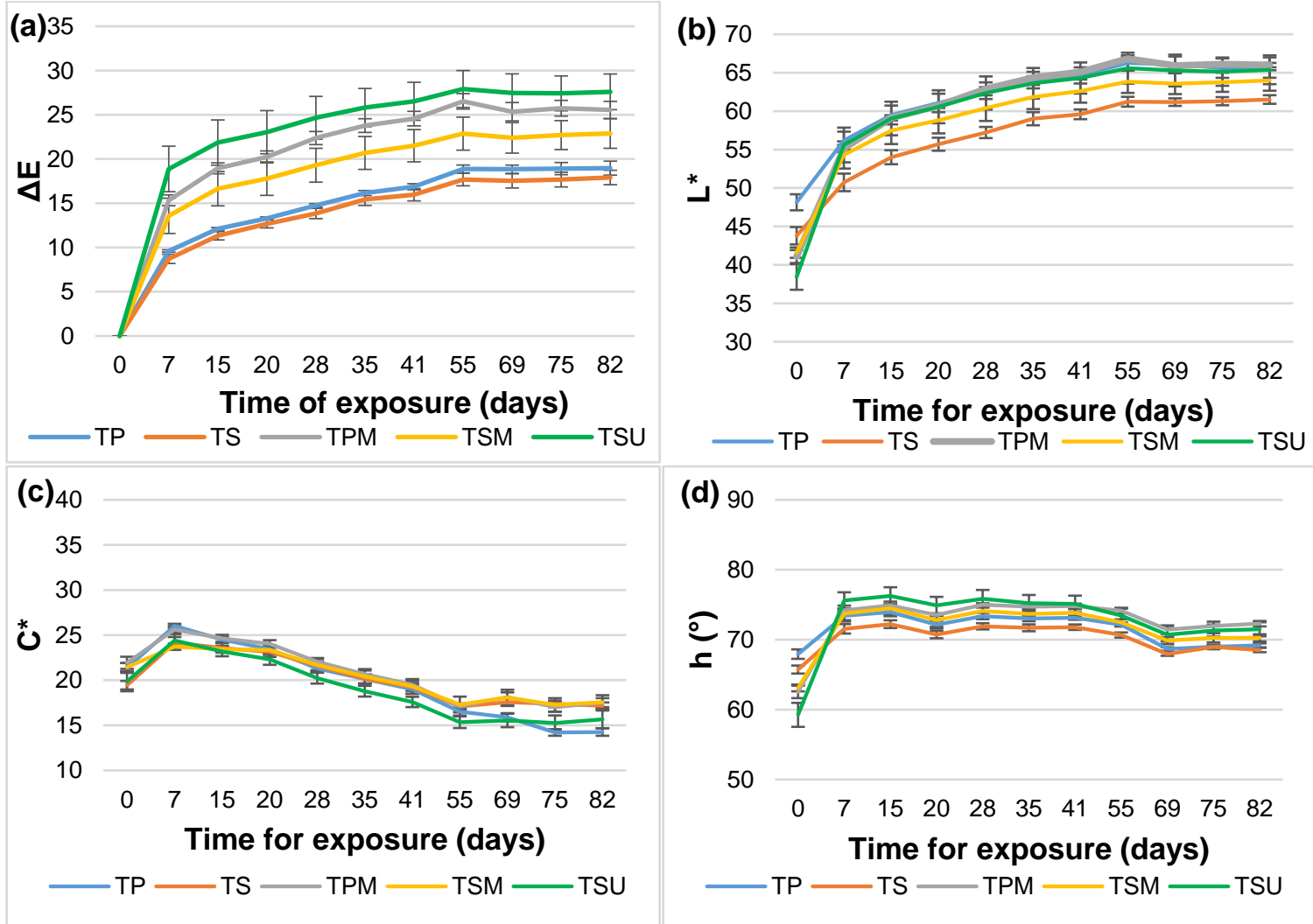

Fig. 6. Color coordinates of thermally modified samples treated with or without MMA resin and exposed outdoors: pine (TP), spruce (TS), pine treated with MMA resin (TPM), spruce treated with MMA resin (TSM), and spruce treated with MMA resin and benzophenone (TSU); a) overall color difference $(\Delta E)$, b) lightness $\left.\left(L^{*}\right), \mathrm{c}\right)$ chroma $\left(C^{\star}\right)$, and d) hue angle $(h)$

In general, thermally modified pine (TP) and spruce (TS) showed less change in color coordinates, while the wood treated with MMA resin showed a considerably larger color change, which could be at least partly due to the somewhat darker initial color of the MMA-treated specimens. The specimens treated with the resin were darker than the untreated specimens before the test (Figs. $3 \mathrm{f}$ and $\mathrm{h}$ ). For example, the average $L^{*}$ value of TP was 48 whereas TPM (TS treated with resin and benzophenone) was 41 . However, after 
outdoor exposure the color of the surfaces did not show any visible differences, and the measured color coordinate values did not show any appreciable difference. However, it seemed clear that the resin did not improve the color stability of thermally treated specimens (Fig. 6).

\section{FTIR Spectroscopy Study}

The FTIR spectra of pine specimens before and after outdoor weathering tests are shown in Fig. 7. The specimens treated with the resin showed an absorption around 1718 to $1719 \mathrm{~cm}^{-1}$, but the intensity of this peak decreased after weathering, which might indicate the removal of resin (Figs. $7 \mathrm{~b}$ and d). The intensity of lignin-associated bands, such as at $1596 \mathrm{~cm}^{-1}, 1511 \mathrm{~cm}^{-1}, 1268 \mathrm{~cm}^{-1}$, and $1220 \mathrm{~cm}^{-1}$ (Faix 1991, 1992; Pandey and Pitman 2003; Müller et al. 2009), either decreased or disappeared after outdoor exposure, which may explain the greyed surfaces of the exposed specimens (Figs. 3 and 4).

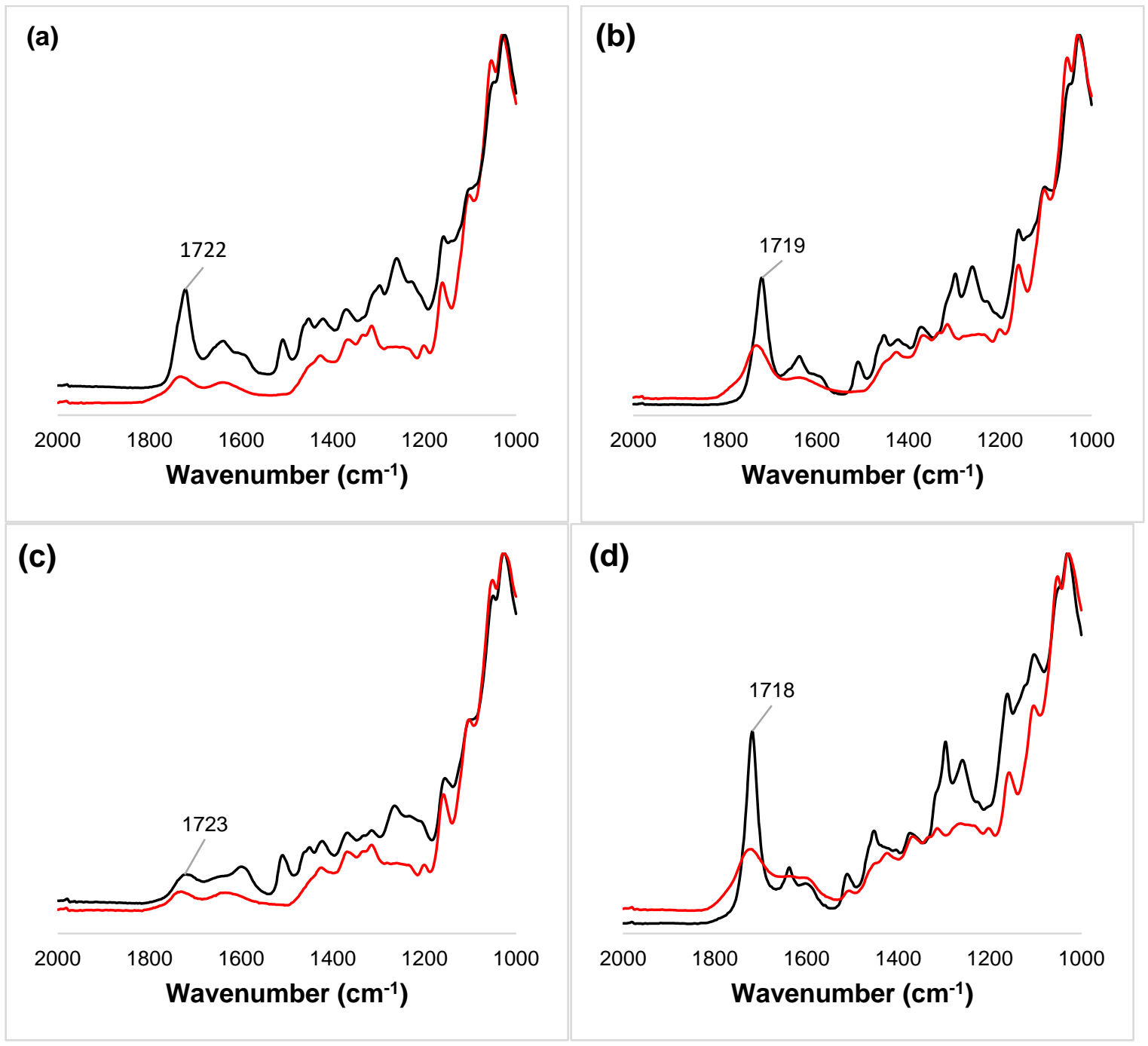

Fig. 7. ATR-FTIR spectra of the surfaces of specimens before (black) and after (red) outdoor weathering for 82 days: a) pine untreated $(P)$, b) pine treated with MMA resin $(P M), c)$ thermally modified pine (TP), and d) thermally modified pine treated with MMA resin (TPM) 
The extent of the absorption at 1722 to $1723 \mathrm{~cm}^{-1}$ was lower for the thermally modified than for the unmodified specimens after outdoor exposure (Figs. 7a and c). Hydrolysis of the acetyl group bond is believed to be caused by thermal modification (Nuopponen et al. 2005), but the FTIR absorption due to ester groups in wood components still seemed to be present, although to a lesser extent (Fig. 7c). Oxidised and water-soluble lignin photodegradation products have been found to absorb in this region (Bejo et al. 2019). However, they contributed to a minor extent in the exposed specimens.

\section{CONCLUSIONS}

1. The methacrylate resin improved the mould resistance but not the discoloration of wood during outdoor exposure, which was presumably because the methacrylate resin was removed by the exposure to outdoor weathering.

2. To prevent mould growth and greying the resin treatment could be applied to wood surfaces that are not directly exposed to sunshine and rain, but where the RH is high, like under a roof or in an attic.

\section{ACKNOWLEDGMENTS}

Financial support from the Swedish Research Council for Environment, Agricultural Sciences and Spatial Planning (FORMAS), project "Fungal growth on modified wood-based products under sub-arctic conditions 2017-00419," is gratefully acknowledged.

\section{REFERENCES CITED}

Balderväder (2020). Statistik: http://balderskolan.se/vader/stat.php

Bejo, L., Tolvaj, L., Kannar, A., and Preklet, E. (2019). "Effect of water leaching on photodegraded spruce wood monitored by IR spectroscopy," J. Photochem Photobiol A: Chem. 382, Paper 111948. DOI: 10.1016/j.jphotochem.2019.111948

Bekhta, P., and Niemz, P. (2005). "Effect of high temperature on the change in color, dimensional stability and mechanical properties of spruce wood," Holzforschung 57(5), 539-546. DOI: 10.1515/HF.2003.080

Brischke, C., and Unger, W. (2017). "Potential hazard and degrading agents," in: Performance of Bio-based Building Materials, D. Jones, and C. Brischke (eds.), Woodhead Publishing, Duxford, England, pp. 188-202.

Browne, F. L., and Simonson, H. (1957). "The penetration of light into wood," Forest Products Journal 7(10), 303-314.

Dagbro, O., Torniainen, P., Karlsson, O., and Morén, T. (2010). “Color responses from wood, thermally modified in superheated steam and pressurized steam atmospheres," Wood Material Science \& Engineering 5(3-4), 211-219. DOI: 10.1080/17480272.2010.520739

Ellis, W. D., and O’Dell, J. L. (1999). "Wood-polymer composites made with acrylic monomers, isocyanate, and maleic anhydride," Journal of Applied Polymer Science 
73(12), 2493-2505. DOI: 10.1002/(SICI)1097-4628(19990919)73:12<2493::AIDAPP18>3.0.CO;2-C

EN 15457 (2014). "Paints and varnishes - Laboratory method for testing the efficacy of film preservatives in a coating against fungi," European Committee for Standardization, Brussels, Belgium.

Esteves, B. M., and Pereira, H. M. (2008). "Wood modification by heat treatment: A review," BioResources 4(1), 370-404. DOI: 10.15376/biores.4.1.370-404

Evans, P. D. (2009). "Review of the weathering and photostability of modified wood," Wood Material Science \& Engineering 4(1-2), 2-13. DOI: 10.1080/17480270903249391

Faix, O. (1991). "Classification of lignins from different botanical origins by FT-IR spectroscopy," Holzforschung 45(S1), 21-28. DOI: 10.1515/hfsg.1991.45.s1.21

Faix, O. (1992). "Fourier transform infrared spectroscopy," in: Methods in Lignin Chemistry, S. Y. Lin, and C. W. Dence (eds.), Springer-Verlag, Berlin, Germany. DOI: 10.1007/978-3-642-74065-7_7

Feist, W. C., and Hon, D. N.-S. (1984). "Chemistry of weathering and protection," in: The Chemistry of Solid Wood, R. Rowell (ed.), American Chemical Society, Washington, DC, USA, pp. 401-451. DOI: 10.1021/ba-1984-0207.ch011

Feist, W. C., Rowell, R. M., and Ellis, W. D. (1991). "Moisture sorption and accelerated weathering of acetylated and methacrylated aspen," Wood and Fiber Science 23(1), 128-136.

Feist, W. C., and Mraz, E. A. (1978). "Comparison of outdoor and accelerated weathering of unprotected softwoods," Forest Products Journal 28(3), 38-43.

Forest Products Laboratory (1975). Wood Finishing: Weathering of Wood (Research Note FPL-0135), U.S. Department of Agriculture Forest Products Laboratory, Forest Service, Madison, WI, USA.

Forsthuber, B., Schaller, C., and Grüll, G. (2013). "Evaluation of the photo stabilising efficiency of clear coatings comprising organic UV absorbers and mineral UV screeners on wood surfaces," Wood Science and Technology 47(2), 281-297. DOI: 10.1007/s00226-012-0487-6

Gierer, J., and Lin, S. Y. (1972). "Photodegradation of lignin. A contribution to the mechanism of chromophore formation," Svensk Papperstidning 75, 233-239.

Hon, D. N.-S. (1981). "Weathering of wood in structural use," in: Proceedings of Second International Conference on Environmental Degradation of Engineering Materials, Virginia Polytechnic Institute, Blacksburg, VA, USA, pp. 519-529.

Hon, D. N.-S., and Minemura, N. (2001). "Color and discoloration," in: Wood and Cellulosic Chemistry, D. N.-S. Hon, and N. Shirashi (eds.), Marcel Dekker, New York, NY, USA, pp. 385-442.

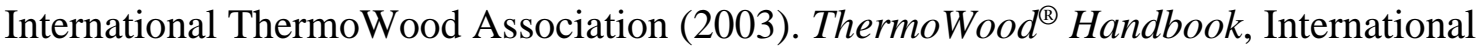
ThermoWood Association, Helsinki, Finland.

Jämsä, S., Ahola, P., and Viitaniemi, P. (2000). "Long-term natural weathering of coated ThermoWood," Pigment \& Resin Technology 29(2), 68-74. DOI: 10.1108/03699420010317807

Jebrane, M., Sèbe, G., Cullis, I., and Evans, P. D. (2009). "Photostabilisation of wood using aromatic vinyl esters," Polymer Degradation and Stability 94(2), 151-157. DOI: 10.1016/j.polymdegradstab.2008.11.013 
Jones, D., Sandberg, D., Goli, G., and Todaro, L. (2019). Wood Modification in Europe: A State-of-the-Art About Processes, Products, Applications, Florence University, Florence, Italy. (In publication)

Karlsson, O., and Moren, T. (2010). "Color stabilization of heat modified Norway spruce exposed to out-door conditions," in: $11^{\text {th }}$ International IUFRO Wood Drying Conference, LTU Skellefteå, Skellefteå, Sweden, pp. 265-268.

Karlsson, O., Myronycheva, O., Jones, D., Sandberg, D., and Elustondo, D. (2018). "Thermally modified wood treated with methacrylate," in: IRG49 International Research Group on Wood Protection Annual Meeting (IRG/WP 18-40849), Johannesburg, South Africa, pp. 1-13.

Karlsson, O., Torniainen, P., Dagbro, O., Granlund, K., and Morén, T. (2012a). "Presence of water-soluble compounds in thermally modified wood: Carbohydrates and furfurals," BioResources 7(3), 3679-3689. DOI: 10.15376/biores.7.3.3679-3689

Karlsson, O., Yang, Q., Sehlstedt-Persson, M., and Morén, T. (2012b). "Heat treatments of high temperature dried Norway spruce boards: Saccharides and furfurals in sapwood surfaces," BioResources 7(2), 2284-2299. DOI: 10.15376/biores.7.2.22842299

Kiguchi, M., and Evans, P. D. (1998). "Photostabilisation of wood surfaces using a grafted benzophenone UV absorber," Polymer Degradation and Stability 61(1), 3345. DOI: 10.1016/S0141-3910(97)00124-9

Koubaa, A., Ding, W., Chaala, A., and Bouafif, H. (2012). "Surface properties of methyl methacrylate hardened hybrid poplar wood," Journal of Applied Polymer Science 123(3), 1428-1436. DOI: 10.1002/app.33799

Li, Y., Wu, Q., Li, J., Liu, Y., Wang, X., and Liu, Z. (2012). "Improvement of dimensional stability of wood via combination treatment: Swelling with maleic anhydride and grafting with glycidyl methacrylate and methyl methacrylate," Holzforschung 66(1), 56-66. DOI: 10.1515/HF.2011.123

Mahltig, B., Arnold, M., and Löthman, P. (2010). "Surface properties of sol-gel treated thermally modified wood," Journal of Sol-Gel Science and Technology 55(2), 221227. DOI: 10.1007/s10971-010-2236-3

Miklečić, J., Blagojević, S. L., Petrič, M., and Jirouš-Rajković, V. (2015). "Influence of $\mathrm{TiO}_{2}$ and $\mathrm{ZnO}$ nanoparticles on properties of waterborne polyacrylate coating exposed to outdoor conditions," Progress in Organic Coatings 89, 67-74. DOI: 10.1016/j.porgcoat.2015.07.016

Müller, G., Schöpper, C., Vos, H., Kharazipour, A., and Polle, A. (2009). "FTIR-ATR spectroscopic analyses of changes in wood properties during particle and fibreboard production of hard- and softwood trees," BioResources 4(1), 49-71. DOI: 10.15376/biores.4.1.49-71

Myronycheva, O., Sehlstedt-Persson, M., Karlsson, O., and Sandberg, D. (2018). "Growth of mold and rot fungi on copper-impregnated scots pine sapwood: Influence of planning depth and inoculation pattern," BioResources 13(4), 8787-8801. DOI: 10.15376/biores.13.4.8787-8801

Myronycheva, O., Poohphajai, F., Sehlstedt-Persson, M., Vikberg, T., Karlsson, O., Junge, H., and Sandberg, D. (2019). "Application of GRAS compounds for the control of mould growth on Scots pine sapwood surfaces: multivariate modelling of mould grade," Forests 10(9), Article number 714. DOI: 10.3390/f10090714

Norrström, H. (1969). “Color of unbleached sulfate pulp,” Svensk Papperstidning 19, 605-619. 
Nuopponen, M., Vuorinen, T., Jämsä, S., and Viitaniemi, P. (2005). "Thermal modifications in softwood studied by FT-IR and UV resonance Raman spectroscopies," Journal of Wood Chemistry and Technology 24(1), 13-26. DOI: 10.1081/WCT-120035941

Nzokou, P., and Kamdem, D. P. (2006). "Influence of wood extractives on the photodiscoloration of wood surfaces exposed to artificial weathering," Color Research and Applications 31(5), 425-434. DOI: 10.1002/col.20248

Olsson, S., Johansson, M., Westin, M., and Östmark, E. (2012). "Grafting of 2-hydroxy4(2,3-epoxypropoxy)-benzophenone and epoxidized soybean oil to wood: Reaction conditions and effects on the color stability of Scots pine," Polymer Degradation and Stability 97(9), 1779-1786. DOI: 10.1016/j.polymdegradstab.2012.06.006

Pandey, K. K., and Chandrashekar, N. (2006). "Photostability of wood surfaces esterified by benzoyl chloride," Journal of Applied Polymer Science 99(5), 2367-2374. DOI: 10.1002/app.22685

Pandey, K. K., and Pitman, A. J. (2003). "FTIR-ATR studies of the changes in wood chemistry following decay by brown-rot and white-rot fungi," International Biodeterioration \& Biodegradation 52(3), 151-160. DOI: 10.1016/S09648305(03)00052-0

Pandey, K. K., and Srinivas, K. (2013). "Study of UV resistance and natural weathering of coatings on chemically modified wood," in: IRG44 International Research Group on Wood Protection Annual Meeting (IRG/WP 13-40629), Stockholm, Sweden, pp. $1-6$.

Pandey, K. K., and Vuorinen, T. (2008). “Comparative study of photodegradation of wood by a UV laser and a xenon light source," Polymer Degradation and Stability 93(12), 2138-2146. DOI: 10.1016/j.polymdegradstab.2008.08.013

Schaller, C., and Rogez, D. (2007). "New approaches in wood coating stabilization," Journal of Coatings Technology and Research 4(4), 401-409. DOI: 10.1007/s11998007-9049-5

Schultz, T. P., Nicholas, D. D., and Preston, A. F. (2007). "A brief review of the past, present, and future of wood preservation," Pest Management Science 63(8), 784-788. DOI: $10.1002 / \mathrm{ps} .1386$

Shen, H., Cao, J., Sun, W., and Peng, Y. (2016). "Influence of post-extraction on photostability of thermally modified scots pine wood during artificial weathering," BioResources 11(2), 4512-4525.

Sidorova, E., Karlsson, O., and Sandberg, D. (2018). "Composition of monosaccharides in aqueous extracts from thermally modified wood," in: $9^{\text {th }}$ European Conference on Wood Modification ECWM9 Proceedings, SHR B.V., Wageningen, Netherlands, pp. 571-580.

Srinivas, K., and Pandey, K.K. (2012). "Photodegradation of thermally modified wood," Journal of Photochemistry and Photobiology B: Biology 117, 140-145.

Tolvaj, L., Nemeth, R., Pasztory, Z., Bejo, L., and Takats, P. (2014). "Color stability of thermally modified wood during short-term photodegradation," BioResources 9(4), 6644-6651. DOI: $10.1006 /$ jcis.2000.6898

Tomak, E. D., Ustaomer, D., Ermezdan, M. A., and Yildiz, S. (2018). "An investigation of surface properties of thermally modified wood during natural weathering for 48 months," Measurement 127, 187-197. 
Tribulová, T., Kačík, F., Evtuguin, D., and Čabalová, I. (2016). “Assessment of chromophores in chemically treated and aged wood by UV-Vis diffuse reflectance spectroscopy," Cellulose Chemistry and Technology 50(5-6), 659-667.

Article submitted: December 29, 2019; Peer review completed: March 28, 2020; Revised version received and accepted: July 21, 2020; Published: July 24, 2020.

DOI: 10.15376/biores.15.3.7018-7033 